\title{
Análise de biomarcadores em tilápias submetidas ao efluente tratado de indústria de carne de frango
}

A indústria de frigoríficos é de fundamental importância na economia mundial, pois mobiliza toda uma cadeia produtiva de alimento que tem como matéria-prima a proteína animal. Porém, como a maioria das atividades industriais, a indústria de frigoríficos também pode gerar problemas ambientais. O tratamento dos efluentes resultantes dos processos produtivos deve ser adequado e eficiente no controle da poluição de modo a não causar prejuízos á biota dos corpos hídricos ao ser lançado no meio ambiente. Quando isso não ocorre, os organismos expostos ao efluente podem sofrer danos irreversíveis. 0 objetivo principal do trabalho foi avaliar, por meio da análise de biomarcadores, efeitos tóxicos causados em peixes da espécie Oreochromis niloticus (Tilápias do Nilo) após serem expostos ao efluente tratado de uma indústria de beneficiamento de carnes de frango localizada no município de Lages, Santa Catarina. $O$ efluente tratado da indústria foi coletado em Abril de 2019 e o teste toxicológico realizado no Laboratório de Toxicologia Ambiental (LABTOX) do curso de Engenharia Ambiental e Sanitária do Centro de Ciências Agroveterinárias (CAV) da Universidade do Estado de Santa Catarina (UDESC). O experimento teve duração de 5 dias (120 horas), sendo testado diluições do efluente de $10 \%, 25 \%, 50 \%$ e $75 \%$. Após esse período foram coletados brânquias, fígado, cérebro e músculo dos organismos para análise das enzimas catalase (CAT), glutationa-S-transferase (GST) e acetilcolenesterase (AChE). Os resultados apontaram poucas alterações dos biomarcadores nos peixes avaliados. Para a AChE, o cérebro e músculo não apresentaram resultados estatisticamente significativos. A CAT teve atividade significativa nas brânquias e fígado dos organismos e a GST teve atividade estatisticamente significativa no músculo e brânquias dos organismos. O efluente tratado da indústria possui uma excelente qualidade e baixa toxicidade para a espécie de peixe testada Tilápia do Nilo (Oreochromis niloticus) e utilizando como parâmetro os biomarcadores de contaminação AChE, CAT e GST.

Palavras-chave: Biomarcadores; Indústria de frigorífico; Toxicidade.

\section{Analysis of biomarkers in tilapiums submitted to treated effluent of a poultry industry}

The poultry industry has fundamental importance in the global economy, as it mobilizes a whole food production chain that has meat as its raw material. However the poultry industry can cause environmental problems as most of the industrial activities. The treatment of effluents must be adequate and efficient in the contro of pollution to avoid damage to the organisms who live into the aquatic environment. When it does not occur, organisms exposed to the effluent may suffer irreversible damage. The main objective of this work was to evaluate, through biomarker analysis, toxic effects caused on fishes Oreochromis niloticus (Nile Tilapia) after being exposed to treated effluent from poultry processing industry located in the municipality of Lages, Santa Catarina. The industry treated effluent was collected in April 2019 and the toxicological test carried out at Environmental Toxicology Laboratory (LABTOX) of the Environmental and Sanitary Engineering course at Center for Agricultural Sciences (CAV) of the Santa Catarina State University (UDESC). The experiment lasted for 5 days (120 hours), being tested the following effluent dilutions: $10 \%, 25 \%, 50 \%$ and $75 \%$. After the test, gills, liver, brain and muscle were collected from the organisms for analysis of catalase (CAT), glutathione-s-transferase (GST) and acetylcholesteresterase (AChE) enzymes. The results showed few changes in the biomarkers of the the evaluated fishes. For AChE, the brain and muscle did not show statistically significant results. CAT had significant activity in the gills and liver of the organisms and GST had statistically significant activity in the muscle and gills of the organisms. The treated effluent from the industry has excellent quality and low toxicity for the tested fish specie Nile Tilapia (Oreochromis niloticus) using as a parameter AChE, CAT and GST biomarkers.

Keywords: Biomarkers; Poultry industry; Toxicity.

Topic: Engenharia Ambiental

Reviewed anonymously in the process of blind peer.
Received: 09/05/2020

Approved: 04/06/2020
Jaqueline Cremonini (D)

Universidade do Estado de Santa Catarina, Brasil

http://lattes.cnpq.br/8948256537102459

http://orcid.org/0000-0003-4369-6784

jaquelinecremonini@hotmail.com

Indianara Fernanda Barcarolli (iD)

Universidade do Estado de Santa Catarina, Brasil

http://lattes.cnpq.br/5914204622450727

http://orcid.org/0000-0003-1420-0524

indianara.barcarolli@udesc.br

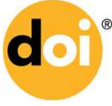

DOI: $10.6008 / C B P C 2179-6858.2020 .004 .0018$
Referencing this:

CREMONINI, J.; BARCAROLLI, I. F.. Análise de biomarcadores em tilápias submetidas ao efluente tratado de indústria de carne de frango. Revista Ibero Americana de Ciências Ambientais, v.11, n.4, p.205-216, 2020. DOI: http://doi.org/10.6008/CBPC21796858.2020.004.0018 


\section{INTRODUÇÃO}

A indústria alimentícia brasileira tem se desenvolvido continuamente, alcançando além de um padrão internacional de qualidade, posições significativas de liderança no "ranking" mundial de mercado e de produção (MORETTO, 2011). Segundo a Associação Brasileira das Indústrias da Alimentação (ABIA), o faturamento da indústria alimentícia brasileira em 2016 foi de R\$ 614,3 bilhões, um crescimento de 9,3\% em relação a 2015 (ABIA, 2017).

Em Santa Catarina, a indústria de carnes foi responsável pelo maior faturamento no Valor Bruto da Produção Agropecuária cerca de R\$12,48 bilhões em 2016 (CIDASC, 2017). O Estado é o maior produtor nacional de carne suína e o segundo maior de carne de frango, atendendo o mercado brasileiro e o exterior, com presença em mais de 120 países (CIDASC, 2017).

A indústria de beneficiamento de carnes de frango é responsável pela produção de congelados de frango como sassami de frango, marinado e assado, empanados de frango pré-fritos e congelados, tiras de peito de frango pré-temperados e assados, filé de peito de frango desfiado, frito e assado, entre outros. A água entra nesse processo na fabricação dos produtos, limpeza de equipamentos, tubulações e pisos, águas de sistema de resfriamento e geradores de vapor, esgotos sanitários dos funcionários e demais partes (AZIZ et al., 2019). Assim, o efluente gerado apresenta uma quantidade elevada de matéria orgânica, sólidos em suspensão, óleo e graxa e nutrientes (BUSTILLO-LECOMPTE et al., 2015).

A não biodegradabilidade está diretamente relacionada com o alto teor de gordura, corantes e aditivos aos processos, que são compostos orgânicos de estrutura complexa, de difícil degradação pelas técnicas convencionais de tratamento, o que vem a ocasionar inibição e/ou paralisação do metabolismo de certos organismos (MORETTO, 2011). A análise de biomarcadores é uma ferramenta utilizada para avaliar alterações fisiológicas de organismos expostos a esse tipo de poluição.

Nesse sentido, esse trabalho teve como objetivo avaliar, por meio da caracterização físico-química do efluente e da análise dos biomarcadores, CAT, GST e AChE, alterações na atividade enzimática de Tilápias do Nilo (Oreochromis niloticus), após serem expostas a diferentes concentrações do efluente tratado de uma indústria de beneficiamento de carnes de frango localizada no município de Lages, Santa Catarina.

\section{MATERIAIS E MÉTODOS}

\section{Coleta e caracterização do efluente tratado}

O efluente tratado foi coletado em Abril de 2019 em uma indústria de beneficiamento de carnes de frango localizada no município de Lages - Santa Catarina. As etapas da estação de tratamento de efluentes podem ser observadas no esquema da Figura 1. A estação de tratamento da indústria é composta pelas etapas de tratamento preliminar, com as peneiras rotativas e o tanque de equalização, tratamento primário, com o flotador e o decantador primário, tratamento secundário, com a presença do tanque de lodos ativados e o decantador secundário e por fim, com a etapa de tratamento do lodo, com a prensa desaguadora, compostagem e envio para o aterro. 


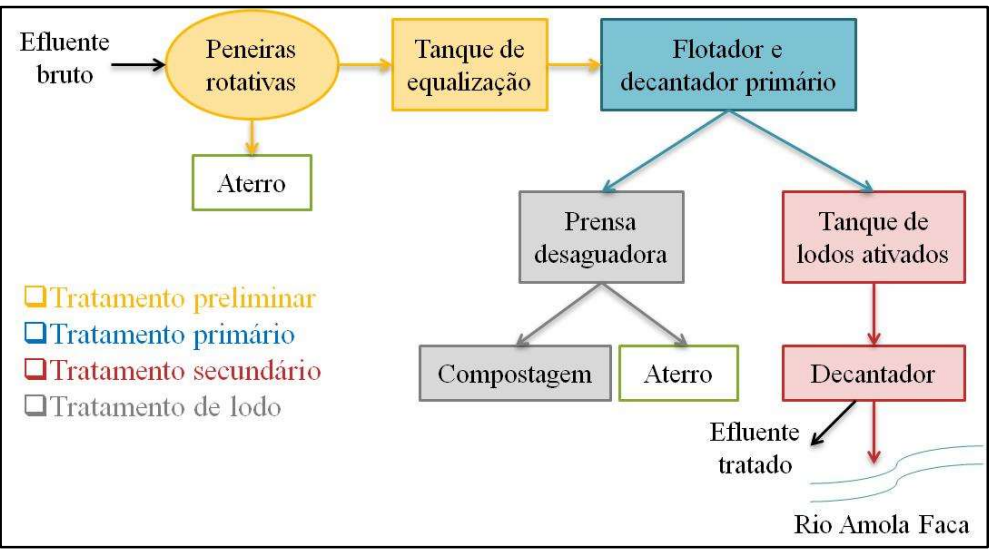

Figura 1: Esquema da estação de tratamento de efluentes da indústria de beneficiamento de carne.

A caracterização de um efluente é obtida a partir de diversos testes que mensuram o teor das substâncias que estão presentes no meio líquido. Os efluentes de qualquer fonte poluidora somente poderão ser lançados diretamente nos corpos receptores após o devido tratamento e desde que obedeçam às condições, padrões e exigências dispostos nas normas brasileiras aplicáveis (CONAMA, 2011).

A Tabela 1 apresenta a média dos resultados das análises físico-químicas de Março e Abril de 2019 do efluente tratado resultante no decantador secundário da indústria de beneficiamento de carne de frango comparados com os valores padrões de lançamento de efluentes dispostos pela Resolução Conama $\mathrm{n}^{\circ}$ $430 / 2011$.

Tabela 1: Média dos resultados das análises físico-químicas de Março e Abril de 2019 do efluente final no tanque de decantação da indústria de beneficiamento de carne de frango e parâmetros do CONAMA n430/2011.

\begin{tabular}{|l|l|l|l|}
\hline Parâmetros & $\begin{array}{l}\text { Efluente Final - Decantador } \\
\text { Março/2019 }\end{array}$ & $\begin{array}{l}\text { Efluente Final - Decantador } \\
\text { Abril/2019 }\end{array}$ & CONAMA $\mathbf{n}^{\circ} \mathbf{4 3 0 / 2 0 1 1}$ \\
\hline Temperatura & $29^{\circ} \mathrm{C}$ & $28^{\circ} \mathrm{C}$ & $<40^{\circ} \mathrm{C}$ \\
\hline pH & 7,5 & 7,0 & 5 e 9 \\
\hline DQO & $123 \mathrm{mg} / \mathrm{L}$ & $120 \mathrm{mg} / \mathrm{L}$ & remoção de 60\% \\
\hline DBO & $39 \mathrm{mg} / \mathrm{L}$ & $28 \mathrm{mg} / \mathrm{L}$ & $120 \mathrm{mg} / \mathrm{L}$ \\
\hline $\mathbf{N O}_{2}-\mathbf{N}$ & $3,1 \mathrm{mg} / \mathrm{L}$ & $0,1 \mathrm{mg} / \mathrm{L}$ & $5 \mathrm{mg} / \mathrm{L}$ \\
\hline $\mathbf{N H}_{3}-\mathbf{N}$ & $15,9 \mathrm{mg} / \mathrm{L}$ & $6,9 \mathrm{mg} / \mathrm{L}$ & $20 \mathrm{mg} / \mathrm{L}$ \\
\hline $\mathbf{N O}_{3}-\mathbf{N}$ & $9,1 \mathrm{mg} / \mathrm{L}$ & $0,9 \mathrm{mg} / \mathrm{L}$ & $10 \mathrm{mg} / \mathrm{L}$ \\
\hline PT & $2,8 \mathrm{mg} / \mathrm{L}$ & $2,8 \mathrm{mg} / \mathrm{L}$ & $10 \mathrm{mg} / \mathrm{L}$ \\
\hline
\end{tabular}

A partir dos resultados da Tabela 1, nota-se que o efluente final no tanque de decantação possui uma ótima qualidade e atende aos parâmetros do CONAMA $n^{\circ}$ 430/2011. Considerando que a média de DQO de efluente bruto de frigorífico é $4.221 \mathrm{mg} / \mathrm{L}$, DBO é $1.209 \mathrm{mg} / \mathrm{l}$, NT é $427 \mathrm{mg} / \mathrm{L}$ e PT é $200 \mathrm{mg} / \mathrm{L}$ (BUSTILLOLECOMPTE et al., 2014; AZIZ et al., 2019), a DQO e DBO do efluente tratado já se encontram bem reduzidas, assim como os resultados dos outros parâmetros como nitrogênio total e fósforo total estão dentro da normalidade.

O desempenho de um reator de batelada sequencial (SBR) tratando águas residuárias de matadouros foi examinado à temperatura ambiente. As águas residuárias afluentes compreenderam $4.672 \mathrm{mg}$ de DQO/L, $356 \mathrm{mg}$ de NT/L e $29 \mathrm{mg}$ de PT/L. A uma taxa de carga orgânica afluente de 1,2 g de DQO/(L.d), as concentrações médias do efluente final de DQO, NT e PT foram de $150 \mathrm{mg} / \mathrm{L}, 15 \mathrm{mg} / \mathrm{L}$ e 0,8 mg/L, respectivamente. Isso representou remoções de DQO, NT e PT de 96\%, 96\% e 99\%, respectivamente (LI et al., 2008). 
Rajab et al. (2017) investigaram em escala laboratorial o desempenho de um reator em batelada sequencial anaeróbio/aeróbio integrado (IAASBR) para o tratamento de águas residuárias de frigorifico. A eficiência média de remoção do IAASBR foi de 97\% da DQO total (DQOT), 95\% da DQO solúvel (DQOS), 98\% do NH3-N, 90\% de gordura, óleos e graxas e $96 \%$ de sólidos suspensos totais (SST).

Aziz et al. (2019) após reunirem diversos estudos na área concluíram que reatores como UASB, filtro anaeróbio, sistema de lodos ativados, reator de biofilme de leito móvel e reator de batelada sequencial foram executados com êxito no tratamento de efluentes de matadouros, porém, reatores de batelada sequencial intermitentes ou em conjuntos sequenciais combinados (anaeróbios e aeróbios) são tecnologias mais eficientes para remoção de carbono, nitrogênio e fósforo do que outros digestores de alta taxa.

\section{Teste de toxicidade}

A aclimatação dos peixes ocorreu em aquários montados no Laboratório de Toxicologia Ambiental (LABTOX) da Universidade do Estado de Santa Catarina (UDESC) durante sete dias. Os 100 peixes foram alimentados uma vez por dia com ração industrial produzida para peixes e estavam sob aeração constante. O teste de toxicidade foi realizado em duplicata sendo para ambas as réplicas o primeiro béquer controle (CTR) e mais 4 béqueres com diferentes diluições do efluente (10\%, 25\%, 50\% e 75\%), conforme pode ser visualizado na Figura 2.

No primeiro béquer (CTR) foi adicionado $2.500 \mathrm{ml}$ de água da rede de abastecimento de água tratada da UDESC, no segundo béquer (10\%) foi adicionado $250 \mathrm{ml}$ de efluente e $2.250 \mathrm{ml}$ de água, no terceiro béquer (25\%) foi adicionado $625 \mathrm{ml}$ de efluente e 1.875 de água, no quarto béquer (50\%) foi adicionado $1.250 \mathrm{ml}$ de efluente e $1.250 \mathrm{ml}$ de água, e por último, no quinto béquer (75\%) foi adicionado $1.875 \mathrm{ml}$ de efluente e 625 $\mathrm{ml}$ de água. Em cada béquer foi adicionado aleatoriamente 6 peixes com o mesmo tamanho e aproximadamente cinco gramas de peso cada um, submetendo-os a aeração mecânica constante durante cinco dias e sem alimentação.

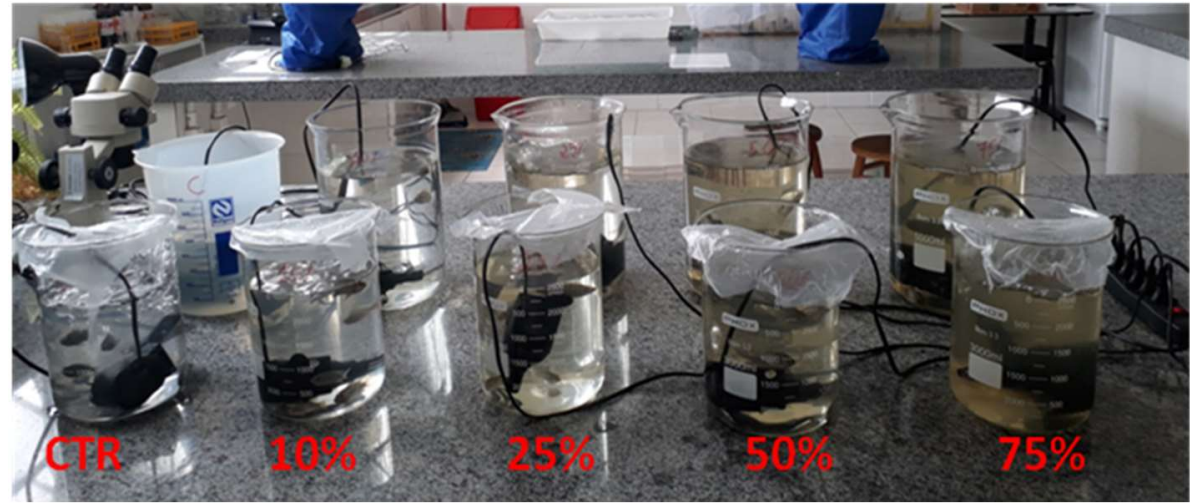

Figura 2: Diluições do efluente para o teste de toxicidade com peixes.

Após os cinco dias, os peixes tiveram os tecidos das brânquias, músculo, cérebro e fígado removidos com material cirúrgico adequado (tesoura e pinça de inox) os quais foram armazenados em tubos de Eppendorf plásticos identificados. Após esse procedimento, os tecidos foram homogeneizados com solução-tampão e por fim, submetidos à refrigeração para evitar a degradação dos tecidos (Figura 3 Figura ). 


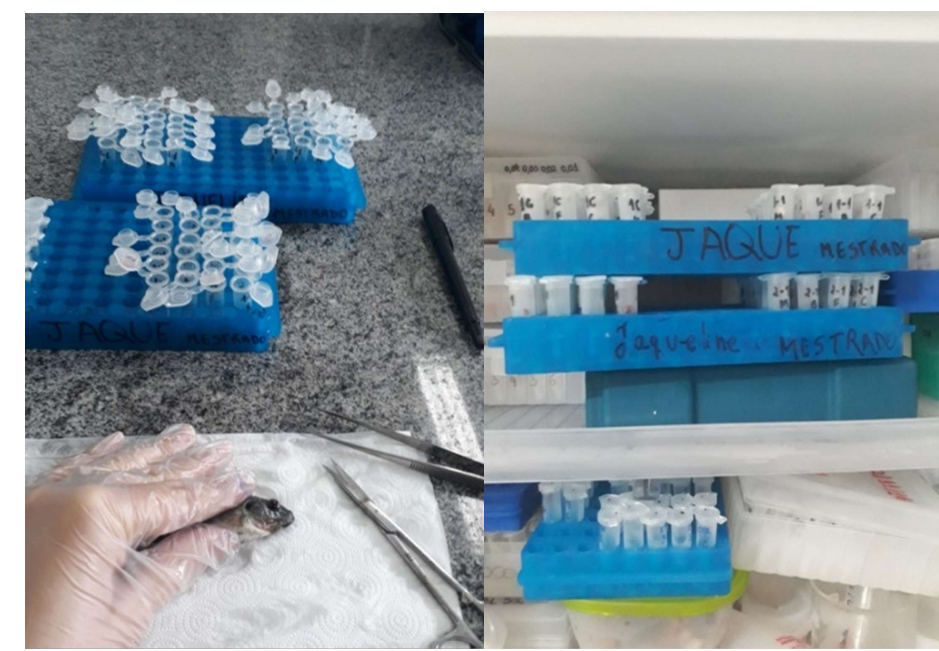

Figura 3: Remoção dos tecidos e refrigeração dos tubos Eppendorf.

\section{Acetilcolinesterase (AChE)}

A atividade da acetilcolinesterase (AChE) que consiste na determinação da taxa de produção de tiocolina. A preparação da reação foi feita através da preparação da solução tampão de fosfato, seguido da preparação do substrato e do reagente de cor. Para preparação da solução tampão de fosfato foi utilizado 8,5 g de $\mathrm{KH}_{2} \mathrm{PO}_{4}$ dissolvido em $250 \mathrm{~mL}$ de água destilada e 2,5 g de hidróxido de sódio ( $\mathrm{NaOH}$ ) em $250 \mathrm{~mL}$ de água destilada. Foi misturado $50 \mathrm{~mL}$ da solução de $\mathrm{KH}_{2} \mathrm{PO}_{4}$ com $39,5 \mathrm{~mL}$ da solução de $\mathrm{NaOH}$ e com ajuste do pH para 7,4.

O substrato foi preparado pesando 5,4 $\mathrm{mg}$ de iodeto de acetilcolina para $1 \mathrm{~mL}$ de água destilada. Como reagente de cor foi dissolvido 39,6 g de ácido 5,5'-ditiois-(2-nitrobenzoato) (DTNB) em $10 \mathrm{~mL}$ de tampão fosfato (0,1M) e após, adicionado $15 \mathrm{mg}$ de bicarbonato de sódio $\left(\mathrm{NaHCO}_{3}\right)$.

Em uma cubeta de polipropileno, foi adicionado 2,0 mL de tampão fosfato, $100,0 \mu \mathrm{L}$ de substrato, 100,0 $\mu \mathrm{L}$ de reagente de cor (DTNB) e 100,0 $\mu \mathrm{L}$ de amostra. No espectrofotômetro foi ajustado o comprimento de onda $412 \mathrm{~nm}$ e serão realizadas 5 leituras com um intervalo de 30 segundos entre elas. Ao final da análise, os valores obtidos foram transferidos para uma planilha eletrônica para o cálculo final da atividade da enzima, determinada por meio da (Equação 1)1:

$$
\text { Atividade da } A C h E=\frac{\Delta \text { Abs amostra } \times 73,03}{Q_{\text {prot }}} \quad \text { (Equação 1) }
$$

\section{Catalase (CAT)}

O protocolo para determinação da atividade da Catalase (CAT) foi proposto por Beutler (1975). Para a solução-tampão da CAT foi utilizado Tris $\mathrm{HCl} 1 \mathrm{M}(\mathrm{PM}=121,1)$, EDTA $5 \mathrm{mM}(\mathrm{PM}=372,24)$ e pH igual 8,0. 0 substrato da reação foi preparado em uma proporção de $100 \mu \mathrm{L}$ de $\mathrm{H}_{2} \mathrm{O}_{2} 30 \%$ em $100 \mathrm{~mL}$ de água destilada. As amostras foram acondicionadas em cubetas de quartzo, onde na cubeta destinada ao branco, foi adicionado 2,0 mL de solução tampão de CAT. Nas demais, foram adicionados 2,0 mL de solução tampão de 
CAT, $20 \mu \mathrm{L}$ da amostra a ser analisada e $20 \mu \mathrm{L}$ de substrato de peróxido de hidrogênio $\left(\mathrm{H}_{2} \mathrm{O}_{2}\right)$.

Em seguida, as leituras foram feitas um espectrofotômetro modelo T70+ da marca PG Instruments Ltda. $O$ comprimento de onda foi ajustado para $240 \mathrm{~nm}$ e foram realizadas 5 leituras com um intervalo de 1 min entre elas. Ao final da análise, os valores obtidos foram transferidos para uma planilha eletrônica para o cálculo final da atividade da enzima, determinada por meio da Equação 2:

$$
\text { Atividade da CAT }=\frac{\Delta \text { Abs da amostra }}{Q_{\text {prot }} \times 0,071 \times 0,01} \quad \text { (Equação 2) }
$$

Sendo que: Atividade da CAT = Atividade da enzima catalase $\left(\mu \mathrm{mol} \mathrm{H}_{2} \mathrm{O}_{2}\right.$ metabolizada $\mathrm{min}^{-1} \mathrm{mg}$ de proteína $\left.{ }^{-1}\right)$; $\triangle$ Abs amostra $=$ Média dos valores de absorbância de cada amostra; $Q_{\text {prot }}=$ Quantidade de proteína para cada amostra $(\mathrm{mg})$.

\section{Glutationa-S-Transferase (GST)}

O protocolo para determinação da atividade da Glutationa-S-Tranferase (GST) foi proposto por Keen et al. (1976). Para a solução tampão de GST foi utilizado: $400 \mathrm{~mL}$ de água destilada, 3,4 g de Fosfato de Potássio Monobásico (PM = 136,09), 4,35 g de Fosfato de Potássio Dibásico $(P M=174,18)$ e pH igual 7,0. Foi diluído um sal de cada vez e após medir o pH, completou-se com água destilada até $500 \mathrm{~mL}$. Após foram preparadas duas soluções como substrato da reação. A primeira solução com a razão de 0,02 g de CNDB (1cloro-2,4-di-nitrobenzene) para 1,0 mL de álcool 100\% e a segunda, uma solução de 0,03 g de GSH para 1,0 $\mathrm{mL}$ de solução tampão GST.

Em uma cubeta de polipropileno, foi adicionado para o branco $2,5 \mathrm{~mL}$ de solução tampão de GSH. Nas demais cubetas, foram adicionados $2,5 \mathrm{~mL}$ de solução tampão, $10 \mu \mathrm{L}$ de amostra, $10 \mu \mathrm{L}$ de substrato de CDNB e $10 \mu \mathrm{L}$ de substrato de GSH. No espectrofotômetro foi ajustado o comprimento de onda $340 \mathrm{~nm}$ e foram realizadas 5 leituras com um intervalo de 1 min entre elas. Ao final da análise, os valores obtidos foram transferidos para uma planilha eletrônica para o cálculo final da atividade da enzima, determinada por meio da (Equação 3)3:

$$
\text { Atividade da GST }=\frac{Q_{\text {prot }} \times 9,6}{\Delta \text { Abs da amostra }} \quad \text { (Equação 3) }
$$

Atividade da GST = Atividade da enzima glutationa-s-transferase ( $\mathrm{nmol}$ CDNB conjugado $\min ^{-1} \mathrm{mg}$ de proteína ${ }^{-1}$; $\triangle$ Abs amostra $=$ Média dos valores de absorbância de cada amostra; $Q_{\text {prot }}=$ Quantidade de proteína para cada amostra $(\mathrm{mg})$.

Os coeficientes utilizados nas equações para determinação da atividade enzimática da AChE, CAT e GST foram obtidos a partir de dados experimentais realizados pelos autores sob condições específicas do experimento que resultaram nas metodologias que foram utilizadas nesse trabalho.

\section{Determinação de proteínas}

Após a realização das análises referentes às atividades enzimáticas (CAT, GST e AChE), foi aferido as absorbâncias dos teores de proteínas de cada amostra pelo método do biureto. Foi adicionado em cubetas, $50 \mu \mathrm{L}$ de amostra, $1,5 \mathrm{~mL}$ do reagente de biureto e 2 gotas de $\mathrm{NaOH}$. $\mathrm{O}$ comprimento de onda do equipamento foi ajustado para $550 \mathrm{~nm}$ e foi feita uma única leitura. Ao final da análise, os valores obtidos 
foram transferidos para uma planilha eletrônica para o cálculo final do teor de proteína em cada amostra, determinada por meio da (Equação 1):

$$
Q_{\text {prot }}=\left(\frac{\Delta \text { Abs da amostra }}{\Delta \text { Abs padrão }}\right) \times 40 \quad \text { (Equação 1) }
$$

Sendo que:

$Q_{\text {prot }}=$ Quantidade de proteína para cada amostra $(\mathrm{mg})$. $\triangle$ Abs amostra = Média dos valores de absorbância de cada amostra; $\Delta$ Abs padrão $=$ Absorbância padrão do equipamento $($ Abs $=0,111)$.

\section{Estatística}

Os resultados das atividades das enzimas CAT, GST e AChE foram submetidas a análise de variância (ANOVA) para comparação das médias das atividades enzimáticas entre as duplicatas pelo Teste Tukey, ao nível de confiança de 95\%, no software de estatística SISVAR 5.6. Com esse procedimento foi verificado que não existia diferença significativa entre as médias das duas duplicatas para todos os testes.

Dessa forma, os resultados obtidos para as duplicatas foram agrupados. Após, foi realizado o intervalo de confiança de $1 \%$ para tirar resultados anômalos e a partir disso, os dados foram submetidos novamente ao teste tukey a ao delineamento dos blocos casualizados. O teste de Tukey tem como base a DMS (diferença mínima significativa). Para dados balanceados a DMS é calculada por meio da Equação 5:

$$
D M S=q_{\alpha}(g, N-g) \sqrt{\frac{Q M E r r o}{n}}
$$

Sendo que:

$\mathrm{n}=$ número de réplicas do tratamento $q \alpha=$ valor tabelado (Tabela do Teste de Tukey) QMErro = quadrado médio do erro.

\section{RESULTADOS}
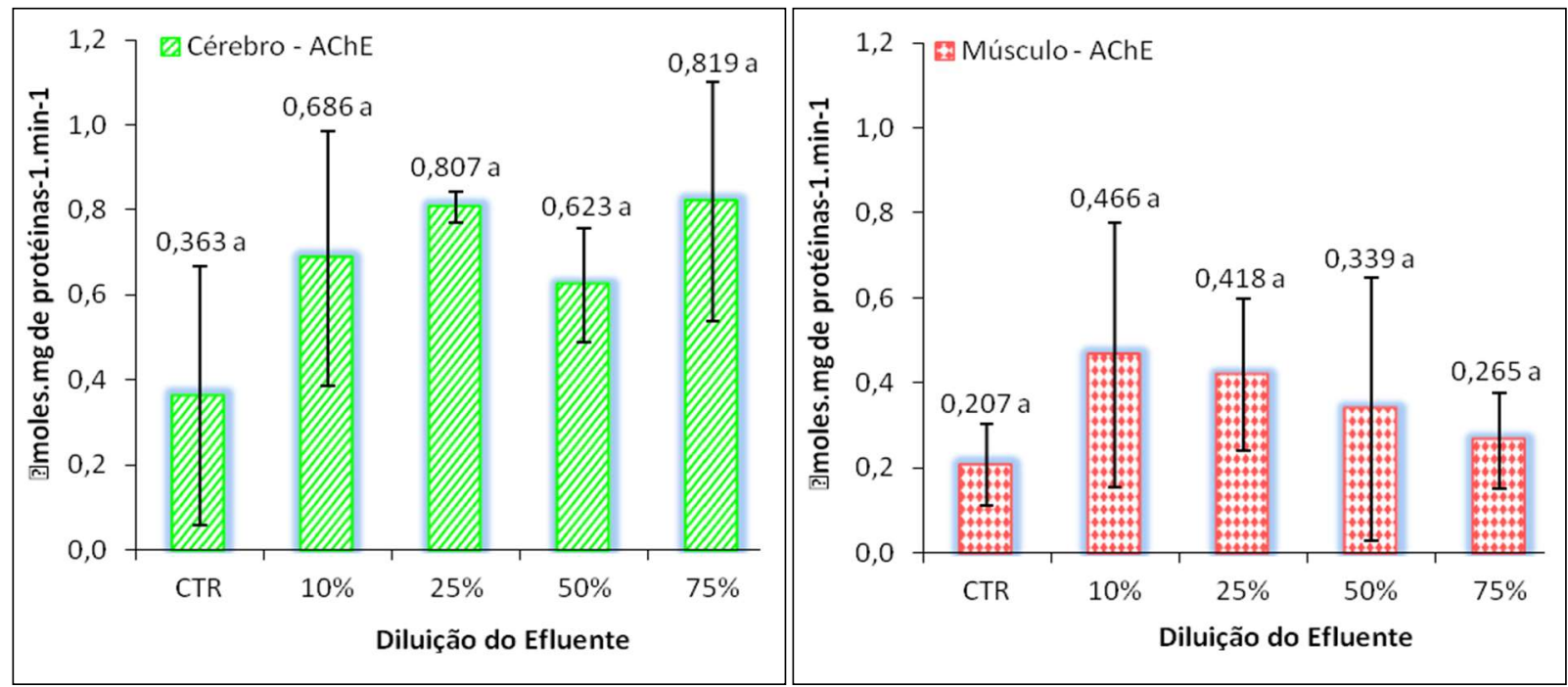

Figura 4: Média e desvio padrão para o cérebro e músculo da enzima AChE.

A Figura 4 apresenta os resultados da atividade média enzimática com o seu respectivo desvio padrão para a acetilcolinesterase (AChE) no cérebro e músculo dos peixes. As médias seguidas da mesma letra não diferem estatisticamente entre si, pelo teste Tukey, ao nível de $5 \%$ de probabilidade, o que significa dizer 
que no teste Tukey de comparação de médias, pode-se afirmar com 95\% de confiança que as médias seguidas de mesma letra são estatisticamente iguais.


Figura 5: Média e desvio padrão para o cérebro, músculo, brânquias e fígado da enzima CAT.
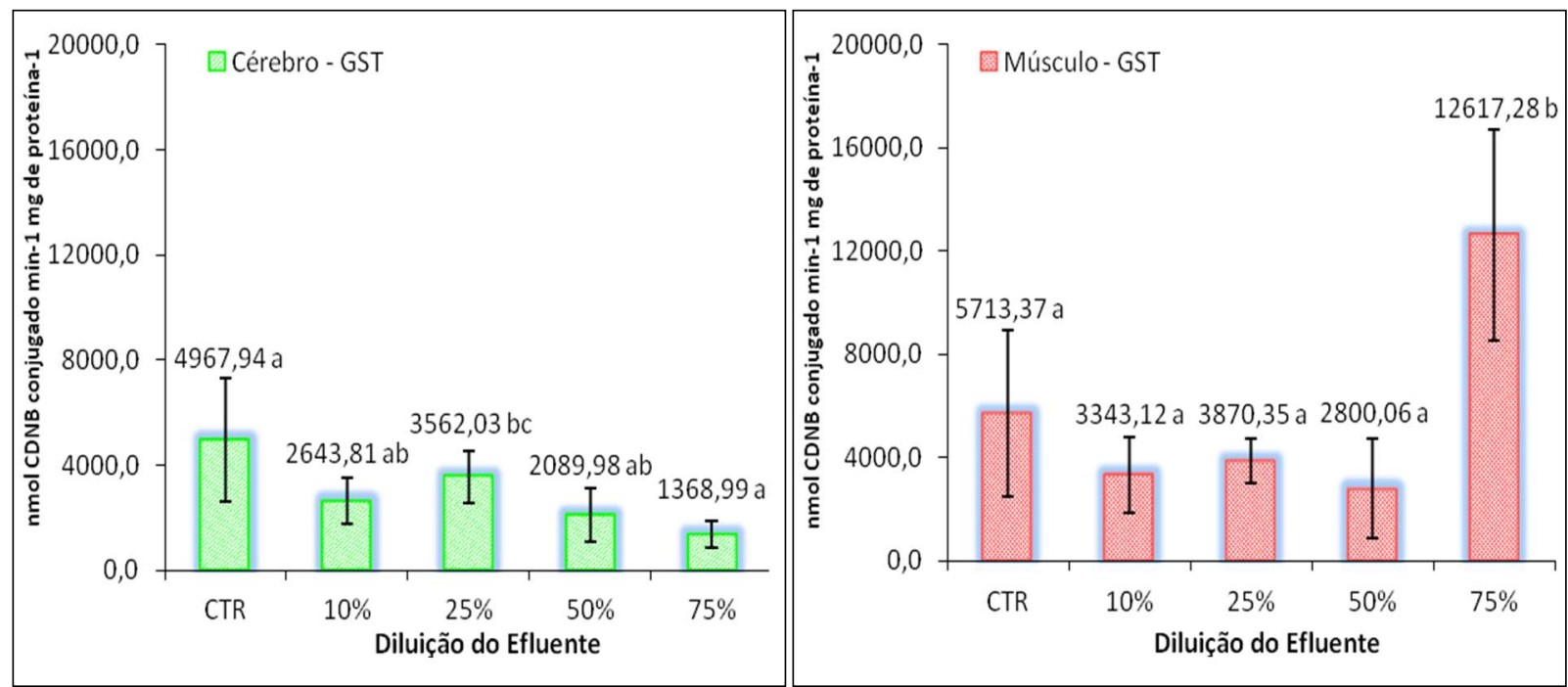


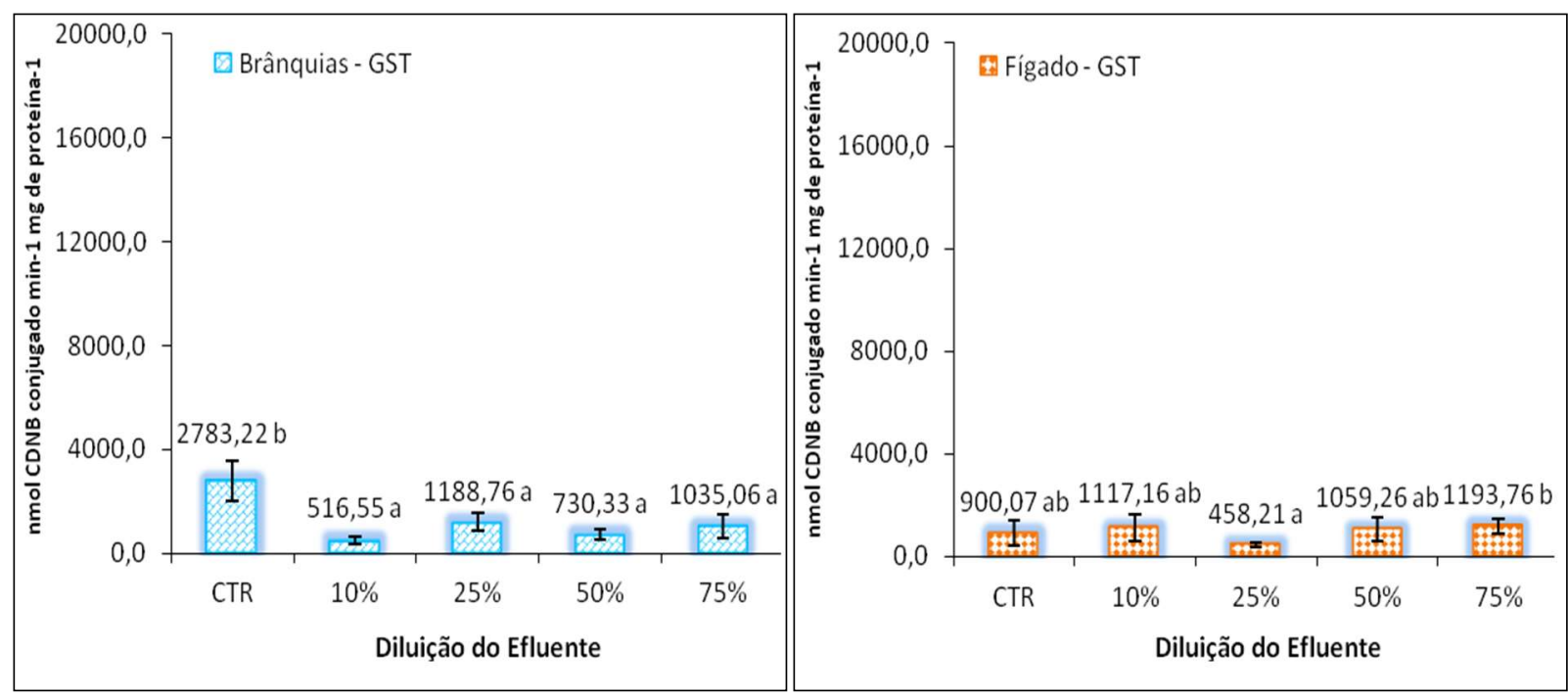

Figura 6: Média e desvio padrão para o cérebro, músculo, brânquias e fígado da enzima GST.

A Figura 5 apresenta os resultados da atividade média enzimática com seu respectivo desvio padrão para a catalase no cérebro, músculo, brânquias e fígado dos peixes. As médias seguidas da mesma letra não diferem estatisticamente entre si, pelo teste Tukey, ao nível de $5 \%$ de probabilidade.

A Figura 6 apresenta os resultados da atividade média enzimática com seu respectivo desvio padrão para a glutationa-S-transferase (GST) no cérebro, músculo, brânquias e fígado dos peixes. As médias seguidas da mesma letra não diferem estatisticamente entre si, pelo teste Tukey, ao nível de $5 \%$ de probabilidade.

\section{DISCUSSÃO}

Os resultados mostraram que a acetilcolinesterase ( $\mathrm{AChE}$ ) teve atividade no cérebro e músculo (Figura 4) dos organismos em relação ao controle, mas esse aumento não foi estatisticamente significativo com as diferentes concentrações do efluente, ao nível de $5 \%$ de probabilidade, sendo portando estatisticamente iguais.

Os resultados da catalase (CAT) apresentados na Figura 5 mostraram que as atividades enzimáticas médias do cérebro e do músculo dos organismos não foram estatisticamente significativas conforme as diluições comparadas ao controle, ao nível de $5 \%$ de probabilidade, o que significa que as médias são estatisticamente iguais.

Nas brânquias, a atividade enzimática média dos organismos variou estatisticamente conforme as diluições em relação ao controle, apresentando uma diferença significativa entre a atividade média da concentração $10 \%$ e a atividade média do controle ao nível de confiança de $95 \%$. No fígado, a atividade enzimática média do fígado dos organismos variou estatisticamente conforme as diluições em relação ao controle, ao nível de $5 \%$ de probabilidade.

Alterações na atividade da catalase indicam que por causa da geração de peróxido de oxigênio nas células devido o contato com compostos químicos, a catalase teve atividade aumentada pois foi necessária sua produção para decompor esse peróxido de oxigênio em água e oxigênio molecular, impedindo que essas espécies reativas de oxigênio (EROs) provocassem as lesões celulares nos tecidos das brânquias e fígado dos 
organismos.

O trabalho de Zanette et al. (2008) comparou a atividade da enzima catalase em brânquias e glândulas digestivas de ostras das espécies Crassostrea rhizophorae e Crassostrea gigas que foram obtidas em quatro pontos distintos de um rio no município de São José, Santa Catarina, de acordo com um gradiente de contaminação por descarga de esgoto doméstico. Os resultados mostraram que a atividade da catalase aumentou em ambos os órgãos da $C$. rhyzophorae conforme aumentava a proximidade com o local de contaminação e a espécie $C$. gigas também apresentou um aumento, mas somente na atividade da enzima branquial.

O estudo realizado por Batista et al. (2014), identificou a resposta da catalase, entre outros biomarcadores, em Astyanax bimaculatus coletados em três pontos distintos (IP, RM e FP) de rios e corpos de água superficiais da bacia hidrográfica do Rio Una. As análises físico-químicas das amostras de água demonstraram uma concentração maior de poluentes, naturais ou antrópicos, para IP e RM em relação à FP, do mesmo modo que os níveis da catalase foram, respectivamente, $148,9 \%$ e $202,4 \%$ maiores nos peixes destes dois pontos (IP e RM) em comparação com os peixes do ponto FP.

Por último, os resultados mostraram que a enzima GST (Figura 6) apresentou inibição estatisticamente significativa no músculo na concentração de $50 \%$ e indução na concentração $75 \%$ e, nas brânquias, a GST teve inibição estatisticamente significativa em relação ao controle em todas as concentrações. No cérebro e no fígado, a atividade enzimática média dos organismos variou estatisticamente conforme as diluições em relação ao controle, ao nível de $5 \%$ de probabilidade.

No músculo, a atividade enzimática média dos organismos variou estatisticamente conforme as diluições, apresentando uma diferença significativa entre a média da concentração $50 \%$ e $75 \%$. Nas brânquias, a atividade enzimática média dos organismos variou estatisticamente conforme as diluições em relação ao controle.

A GST é a principal enzima na fase II do processo de detoxificação celular, que catalisa a conjugação de eletrófilos com o tiol reativo hidrofílico da glutationa (GSH), facilitando o mecanismo de excreção de xenobióticos (BATHIGE et al., 2014). O fígado é a principal fonte de GST em peixes, onde essa enzima corresponde a uma grande fração das proteínas hepáticas solúveis. A atividade da GST também já foi descrita em órgãos extra-hepáticos de peixes, entretanto sua atividade nesses tecidos é geralmente menor do que no fígado (MARTINEZ, 2006).

A atividade aumentada da GST pode estar associada a um processo adaptativo do organismo à presença de uma variedade de compostos orgânicos no ambiente, indicando que os resultados da GST devem ser analisados de forma cuidadosa e sempre associados com os resultados de outros biomarcadores bioquímicos (GALLAGHER et al., 2001).

Foi relatado um aumento na atividade hepática do GST em vários estudos após a exposição de peixes a PAHs, PCBs, OCPs e PCDDs, mas a maioria dos estudos não demonstrou alterações estatisticamente significativas entre peixes de locais poluídos e o controle. Foi observada uma diminuição significativa nas atividades de GST em truta arco-íris, robalo, dourada e peixes-sol expostos PCDDs, pesticidas ou HAPs, e em 
algumas espécies de peixes em ambientes poluídos (OOST et al., 2003).

Dessa forma, a utilização da atividade total da GST como biomarcador para avaliação de risco ambiental ou ecológico é limitada a algumas espécies de peixes e, ainda, a exposição a certos compostos pode causar tanto a indução quanto a inibição da atividade enzimática (OOST et al., 2003).

\section{CONCLUSÕES}

As conclusões do trabalho foram obtidas a partir dos resultados de Março e Abril das análises físicoquímicas do efluente tratado e dos resultados da análise dos biomarcadores catalase, glutationa-Stransferase e acetilcolinesterase no peixe tilápia (Oreochromis niloticus) após serem submetidas a esse efluente tratado. $O$ efluente da parte físico-química apresentou uma qualidade excelente indicando que o tratamento utilizado está sendo eficiente na remoção dos compostos orgânicos e inorgânicos do efluente. Como consequência, observaram-se poucas alterações dos biomarcadores no organismo dos peixes avaliados.

Para a acetilcolinesterase, o cérebro e músculo não apresentaram resultados estatisticamente significativos. A catalase teve atividade significativa nas brânquias e fígado dos organismos e a glutationa-Stransferase teve atividade estatisticamente significativa no músculo e brânquias dos organismos. Dessa forma, os resultados apresentados neste trabalho mostraram que o efluente tratado da indústria, após ser submetido a todas as etapas do sistema de tratamento de efluentes, possui uma excelente qualidade e poucas alterações significativas foram observadas nos biomarcadores de contaminação catalase, glutationaS-transferase e acetilcolinesterase na espécie de peixe testada Tilápia do Nilo (Oreochromis niloticus).

\section{REFERÊNCIAS}

ABIA. Associação Brasileira das Indústrias da Alimentação. ABIA divulga balanço do setor de alimentos e bebidas. ABIA, 2017

AZIZ, A.; BASHEER, F.; SENGAR, A.; IRFANULLAH; KHAN, S. U. FAROOQI, I. H.. Biological wastewater treatment (anaerobicaerobic) technologies for safe discharge of treated slaughterhouse and meat processing wastewater. Science of the Total Environment, v.686, p.681-708, 2019. DOI: http://dx.doi.org/10.1016/j.scitotenv.2019.05.295

BATISTA, M. T. O.; VANI, G. S.; RODRIGUES JUNIOR, E.; FEIJÓOLIVEIRA, M.; RIBEIRO, A. C.; RODRIGUES, E.; SUDA, C. N. K.. Tissue levels of the antioxidant enzymes superoxide dismutase and catalase in fish Astyanax bimaculatus from the Una River Basin. Ambiente e Agua - An Interdisciplinary Journal of Applied Science, v.9, n.4, 2014. DOI: http://dx.doi.org/10.4136/ambi-agua.1473

BATHIGE, S. D. N. K.; UMASUTHAN, N.; REVATHY, K. S.; LEE Y.; KIM, S.; CHO, M. Y.; PARK, M.; WHANG, I.; LEE, J.. A mu class glutathione $\mathrm{S}$-transferase from Manila clam Ruditapes philippinarum (RpGST $\mu$ ): cloning, mrna expression, and conjugation assays. : Cloning, mRNA expression, and conjugation assays. Comparative Biochemistry And Physiology Part C: Toxicology \& Pharmacology, v.162, p.8595, 2014. DOI: http://dx.doi.org/10.1016/j.cbpc.2014.03.007
BEUTLER, E.. Red Cell Metabolism: A manual of biochemical methods. New York: Grune \& Straton, 1975

BUSTILLO-LECOMPTE, C. F.; MEHRVAR, M.; QUIÑONESBOLAÑOS, E.. Cost-effectiveness analysis of TOC removal from slaughterhouse wastewater using combined anaerobic-aerobic and UV/H2O2 processes. Journal of Environmental Management, v.134, p.145-152, 2014. DOI: http://dx.doi.org/10.1016/j.jenvman.2013.12.035

BUSTILLO-LECOMPTE, C. F.; MEHRVAR, M.. Slaughterhouse wastewater characteristics, treatment, and management in the meat processing industry: a review on trends and advances. : A review on trends and advances. Journal of Environmental Management, v.161, p.287-302, 2015. DOI: http://dx.doi.org/10.1016/j.jenvman.2015.07.008

CIDASC. Companhia Integrada de Desenvolvimento Agrícola de Santa Catarina. Boletim Agropecuário traz panorama da produção de carnes em Santa Catarina. CIDASC, 2017.

CONAMA. Conselho Nacional de Meio Ambiente. Resolução n. 430, de 13 de maio de 2011. Dispõe sobre as condições e padrões de lançamento de efluentes, complementa e altera a Resolução no 357, de 17 de março de 2005, do Conselho Nacional do Meio Ambiente. CONAMA, 2011. 
GALLAGHER, E. P.; GROSS, T. S.; SHEEHY, K. M.. Decreased glutathione $S$-transferase expression and activity and altered sex steroids in Lake Apopka brown bullheads (Ameiurus nebulosus). Aquatic Toxicology, v.55, n.3-4, p.223-237, 2001. DOI: http://dx.doi.org/10.1016/s0166-445x(01)00158$\underline{8}$

KEEN, J. H.; HABIG, W. H.; JAKOBY, W. B.. Mechanism for several activities of the glutatione-S-transferase. Journal Biology Chemical, v.20, p.6138-6188. 1976.

LI, J. P.; HEALY, M. G.; ZHAN, X. M.; RODGERS, M.. Nutrient removal from slaughterhouse wastewater in an intermittently aerated sequencing batch reactor. Bioresource Technology, v.99, n.16, p.7644-7650, 2008. DOI: http://dx.doi.org/10.1016/j.biortech.2008.02.001

MARTINEZ, C. B. R.. Parâmetros bioquímicos de peixes para avaliação da qualidade da água. Londrina: Universidade Estadual de Londrina, 2006.

MORETTO, D.. Avaliação da remoção de pigmentação de calda de indústria de balas utilizando peróxido de hidrogênio promovido com íon hidroxila. Dissertação
(Mestrado em Engenharia de Alimentos) - Universidade Regional Integrada do Alto Uruguai e das Missões, Erechim, 2011.

RAJAB, A. R.; SALIM, M. R.; SOHAILI, J.; ANUAR, A. N.; SALMIATI; LAKKABOYANA, S. K.. Performance of integrated anaerobic/aerobic sequencing batch reactor treating poultry slaughterhouse wastewater. Chemical Engineering Journal, v.313, p.967-974, 2017. DOI:

http://dx.doi.org/10.1016/i.cej.2016.10.144

OOST, R. V. D.; BEYER, J.; VERMEULEN, N. P. E.. Fish bioaccumulation and biomarkers in environmental risk assessment: a review. Environmental Toxicology and Pharmacology, v.13, n.2, p.57-149, 2003. DOI: http://dx.doi.org/10.1016/s1382-6689(02)00126-6

ZANETTE, J.; NUNES, F. F.; MEDEIROS, I. D.; SIEBERT, M. N.; MATTOS, J. J.; LÜCHMANN, K. H.; MELO, C. M. R.; BAINY, A. C. D.. Comparison of the antioxidant defense system in Crassostrea rhizophorae and Crassostrea gigas exposed to domestic sewage discharges. Marine Environmental Research, v.66, n.1, p.196-198, 2008. DOI: http://dx.doi.org/10.1016/j.marenvres.2008.02.057

A CBPC - Companhia Brasileira de Produção Científica (CNPJ: 11.221.422/0001-03) detém os direitos materiais desta publicação. Os direitos referem-se à publicação do trabalho em qualquer parte do mundo, incluindo os direitos às renovaç̃oes, expansões e disseminações da contribuiç̃o, bem como outros direitos subsidiários. Todos os trabalhos publicados eletronicamente poderão posteriormente ser publicados em coletâneas impressas sob coordenação da Sustenere Publishing, da Companhia Brasileira de Produção Científica e seus parceiros autorizados. Os (as) autores (as) preservam os direitos autorais, mas não têm permissão para a publicação da contribuição em outro meio, impresso ou digital, em português ou em tradução. 